\title{
The effects of estrogen administration on bone mineral density in adolescents with anorexia nervosa
}

\author{
M T Muñoz ${ }^{1}$, G Morandé ${ }^{3}$, J A García-Centenera ${ }^{4}$, F Hervás ${ }^{4}$, J Pozo ${ }^{1}$ and J Argente ${ }^{1,2}$ \\ ${ }^{1}$ Division of Pediatric Endocrinology, ${ }^{2}$ Laboratory of Research, Universidad Autónoma, Department of Pediatrics, Hospital Universitario Niño Jesús, \\ ${ }^{3}$ Division of Pediatric Psychiatry and ${ }^{4}$ Division of Endocrinology, Hospital Santa Cristina, Madrid, Spain \\ (Correspondence should be addressed to J Argente, Hospital Universitario Niño Jesús, Department of Endocrinology, Avda Menéndez Pelayo, 65, 28009 \\ Madrid, Spain; Email: argenteFEN@teleline.es)
}

\begin{abstract}
Objective: Profound osteopenia is a serious complication of anorexia nervosa (AN). The aim of this work was to study the effect of prolonged AN on lumbar spine bone mineral density (BMD) and to determine whether oral estrogen administration prevents bone loss in women with this disorder.

Subjects and Methods: Thirty-eight amenorrheic women with AN (mean age: 17.3 years) were treated with estrogen $(50 \mu \mathrm{g}$ of ethinyl estradiol $)$ and gestagen $(0.5 \mathrm{mg}$ of norgestrel) during 1 year. Clinical variations, biochemical indices and BMD were studied at three different time points, including after a period of amenorrhea of at least 12 months $(n=38)$, after the administration of estrogens for 1 year $(n=22)$, and after a 1-year follow-up period $(n=12)$.

Results: Initial mean BMD was significantly lower than normal $(-2.1 \pm 0.8$ S.D. $)$ and less than -2.5 S.D. below normal in $38 \%$ of the women with AN. The estrogen-treated group had no significant change in BMD even after the follow-up period and partial recovery of weight. Estradiol and total IGF-I levels were significantly lower throughout the study. All subjects had normal thyroxine $\left(\mathrm{T}_{4}\right)$ and TSH levels and calcium metabolism. However, total tri-iodothyronine $\left(\mathrm{T}_{3}\right)$ was decreased in all anorexic subjects in the first and second study points and were within normal limits after the follow-up period.

Conclusions: (1) Estrogen replacement alone cannot prevent progressive osteopenia in young women with AN. (2) Other factors, such as the loss of weight, the duration of the amenorrhea and the low levels of total insulin-like growth factor-I (IGF-I) could contribute to the loss of bone mass in women with this disorder.
\end{abstract}

European Journal of Endocrinology 146 45-50

\section{Introduction}

Prolonged amenorrhea is a complication present in the majority of patients with anorexia nervosa (AN) (1). Osteoporosis is another important medical complication commonly associated with AN. Adolescence is a particularly critical time for bone mineral accretion, as more than half of the bone calcium is normally laid down during the teenage years. Hence, AN may result in profound deficits in bone mass which may not be fully reversible. The pathogenesis of osteoporosis in AN has not been completely characterized. While low body mass and amenorrhea are clearly important variables, other factors, such as low calcium intake, increased levels of glucocorticoids and insulin-like growth factor-I (IGF-I) deficiency (2), may also be involved.

There is some published data on trabecular bone mineral density (BMD) in adult women with AN (3, 4), but it is still unknown whether there is a progressive or permanent decline in bone mass. Although the role of estrogen replacement therapy in preventing bone loss in menopausal women has been clearly established, no studies have been carried out to determine whether it is beneficial in young women with premenopausal osteopenia.

The aim of this study was to determine whether oral estrogens improve BMD in anorexic patients with osteopenia.

\section{Subjects and methods}

\section{Study protocol}

We studied 38 amenorrheic women with AN, as defined by the DSM-IV criteria from the latest Diagnostic and Statistical Manual of Mental Disorders of the American Psychiatry Association (5). The mean ages of the controls and patients with AN were 17.3 \pm 0.4 and 17.4 1.5 years respectively. Every patient consulted the 
Division of Endocrinology of our hospital after the diagnosis of AN was made at the Division of Psychiatry of the same hospital. All normal subjects were referred to the Division of Endocrinology for suspected endocrine abnormalities and were found to be normal with a height and weight between -1 and +1 S.D. according to Spanish standards (6). The study subjects were investigated at three different time points: $\mathrm{T} 1=$ after a period of amenorrhea of at least 12 months $(n=38)$, T2 $=$ after the administration of estrogens $(50 \mu \mathrm{g}$ of ethinyl estradiol) and gestagens ( $0.5 \mathrm{mg}$ of norgestrel) during 1 year $(n=22)$, and T3 = after a follow-up period of 1 year $(n=12)$. No patient had previously received treatment with estrogens. In all subjects amenorrhea occurred in close temporal association with the onset of anorexia. No patient had any other illness or was taking any medication known to affect bone mass, including thyroid hormones, anti-seizure medications or glucocorticoids. In addition, all of the patients had reached their target height when the diagnosis was made.

All patients were scheduled for a complete history, including details regarding menstrual function, age of menarche, exercise, alcohol use, other medications and a physical examination. The body mass index (BMI) was calculated as weight $(\mathrm{kg}) /$ height $(\mathrm{m})^{2}$. The BMI score was based upon normative data from Spanish women (6). After the first visit, the patients received treatment with ethinyl estradiol ( $50 \mu \mathrm{g} /$ day $)$ and gestagens $(0.5 \mathrm{mg}$ norgestrel). Treatment compliance was evaluated every 3 months through clinical controls. All subjects were informed of the purpose of the study and gave consent as required by the local human ethics committee.

\section{Hormone assays}

A gonadotrophin-releasing hormone (GnRH) stimulation test was performed (100 $\mu \mathrm{g}$ i.v. Luforan) for the determination of follicle-stimulating hormone (FSH) and luteinizing hormone $(\mathrm{LH})$. Blood samples were obtained at $-30,0,30,60,90$ and $120 \mathrm{~min}$ after the administration of GnRH. Serum FSH and LH measurements were performed by immonoradiometric assay (IRMA; Sorin, Biomédica, Vercelli, Italy). Serum estradiol levels were measured by RIA (Diagnostic Products Corporation, Los Angeles, CA, USA). Total IGF-I levels were determined by RIA (Nichols Laboratories, San Juan Capistrano, CA, USA) after acid-ethanol extraction of serum. Measurements of tri-iodothyronine $\left(\mathrm{T}_{3}\right)$, thyroxine $\left(\mathrm{T}_{4}\right)$ and thyrotrophin (TSH) were performed by using RIA. In these samples, serum levels of calcium, phosphate, tartrate-resistant acid phosphatase, parathyroid hormone (PTH) and osteocalcin were also measured. The calcium and phosphate were determined by an autoanalyzer Vitros 750 (Johnson \& Johnson). Tartrate-resistant acid phosphatase measurements were performed by kinetic reaction inhibiting its activity by adding tartrate. The PTH and osteocalcin were performed by chemiluminescence (Imulite, DPC). Intraand interassay coefficients of variation were $2.75 \%$ and $3.5 \%$ for $\mathrm{FSH}, 2.75 \%$ and $3.17 \%$ for $\mathrm{LH}, 5.3 \%$ and $6.4 \%$ for estradiol, $4.9 \%$ and $8.9 \%$ for IGF-I, $4.8 \%$ and $6 \%$ for PTH, and $5.2 \%$ and $6.2 \%$ for osteocalcin.

\section{BMD}

$\operatorname{BMD}\left(\mathrm{g} / \mathrm{cm}^{2}\right)$ of the lumbar spine $\left(\mathrm{L}_{2}-\mathrm{L}_{4}\right)$ was measured by Dual-Energy X Ray Absorptiometry with a Lunar DPX-L-densitometer model at the three different points of the study. Z-score data (measured result - population mean/standard deviation) were calculated for all patients using normative data of a standard Spanish population of girls between 15 and 20 years old. The control group consisted of 14 women, Tanner V, of similar age, with regular menses and with no history of food disorders (7).

\section{Statistical analysis}

All data are reported as the mean \pm s.E.M. When only two experimental groups were compared, Student's test was applied. For more than two experimental groups, analysis was performed by a one-way ANOVA or ANOVA with repeated measures, followed by Scheffé's $F$ test. Correlations were performed using simple regression analysis. $P<0.05$ was chosen as the level of significance.

\section{Results}

\section{Clinical and auxological data}

Of the 38 women who entered the study, 22 completed the treatment. The secondary amenorrhea had a mean duration of $2 \pm 1$ years. At the beginning of the study, the relationship between weight/height, expressed in S.D. of the BMI for age and sex, was $-1.4 \pm 0.5$ (Table 1) and the interval between menarche and the onset of the amenorrhea was $2.6 \pm 0.8$ years.

\section{Hormone studies}

Basal and GnRH-stimulated FSH and LH levels were within the normal limits when compared with the corresponding control group of the same age and sex at the beginning of the follicular phase $(\mathrm{FSH}$ basal $=$ $5.7 \pm 3 \mathrm{mUI} / \mathrm{ml} ; \quad \mathrm{FSH} \quad$ peak $=13 \pm 6 \mathrm{mUI} / \mathrm{ml} ; \quad \mathrm{LH}$ basal $=4.7 \pm 4 \mathrm{mUI} / \mathrm{ml}$; $\mathrm{LH}$ peak $=46 \pm 24 \mathrm{mUI} / \mathrm{ml}$ ). Estradiol levels were significantly lower at all three time points of the study: $\mathrm{T} 1=28 \pm 15 \mathrm{pg} / \mathrm{ml} ; \mathrm{T} 2$ $($ after treatment $)=28 \pm 15 \mathrm{pg} / \mathrm{ml} ; \mathrm{T} 3 \quad$ (follow-up) $=$ $25 \pm 18 \mathrm{pg} / \mathrm{ml}$ (Table 2). Serum IGF-I concentrations were significantly lower throughout the study $(\mathrm{T} 1=344 \pm 113 \mathrm{ng} / \mathrm{ml} ; \quad \mathrm{T} 2=349 \pm 84 \mathrm{ng} / \mathrm{ml} ; \mathrm{T} 3=$ $361 \pm 24 \mathrm{ng} / \mathrm{ml}$ ) (Fig. 1). All subjects had normal total 
Table 1 BMI, calcium, phosphate, tartrate-resistant acid phosphatase (FaTr) and PTH serum levels. Values are means \pm S.E.M.S.

\begin{tabular}{lccccc}
\hline & $\begin{array}{c}\text { BMI } \\
(\text { S.D. })^{*}\end{array}$ & $\begin{array}{c}\text { Calcium } \\
(\mathrm{mg} / \mathrm{dl})\end{array}$ & $\begin{array}{c}\text { Phosphate } \\
(\mathrm{mg} / \mathrm{dl})\end{array}$ & $\begin{array}{c}\text { FaTr } \\
(\text { IU) }\end{array}$ & $\begin{array}{c}\text { PTH } \\
(\mathrm{ng} / \mathrm{ml})\end{array}$ \\
\hline Initial $(n=38)$ & $-1.4 \pm 0.5$ & $9.6 \pm 0.5$ & $4.0 \pm 0.6$ & $3.8 \pm 1.0$ & $37 \pm 21$ \\
Final $(n=22)$ & $-0.9 \pm 0.8$ & $9.9 \pm 0.5$ & $4.0 \pm 0.6$ & $2.4 \pm 0.5$ & $35 \pm 16$ \\
Follow-up $(n=12)$ & $-0.6 \pm 0.9$ & $9.8 \pm 0.5$ & $4.0 \pm 0.3$ & $2.2 \pm 0.5$ & $35 \pm 10$ \\
\hline
\end{tabular}

*Values are the means of the S.D.S of the BMI of age and sex ( \pm S.E.M.S).

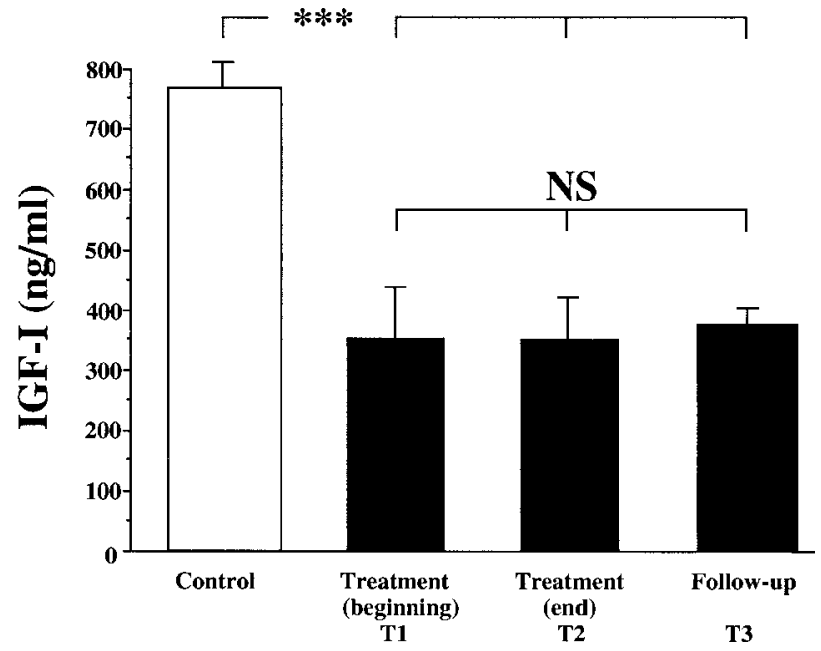

Figure 1 Schematic representation of mean \pm S.D. serum levels of total IGF-I in patients with AN. Initial, final and follow-up periods in estrogen-treated patients $\left({ }^{\star * \star} P<0.01\right)$.

$\mathrm{T}_{4}$ and TSH levels (Table 2); however, total $\mathrm{T}_{3}$ was decreased in all subjects during the first and second time periods of the study and were within normal limits after the follow-up period $(\mathrm{T} 1=0.8 \pm 0.2 \mathrm{ng} / \mathrm{ml}$; $\mathrm{T} 2=0.9 \pm 0.1 \mathrm{ng} / \mathrm{ml} ; \mathrm{T} 3=1 \pm 0.1 \mathrm{ng} / \mathrm{ml}$ ) (Fig. 2).

Calcium, phosphate, tartrate-resistant acid phosphatase, PTH and osteocalcin levels were within the limits of normality at all three time points (Table 1).

\section{BMD}

At the beginning of the study, the lumbar spine BMD mean was $-2.1 \pm 0.8$ (range: -3.7 to -0.5 S.D.). After a year of treatment with estrogens the BMD was $-1.8 \pm 0.8$ S.D. (range -3.4 to -0.3 S.D.) in the 22 patients that completed this stage. There was no difference in these patients in their starting BMD and after 1

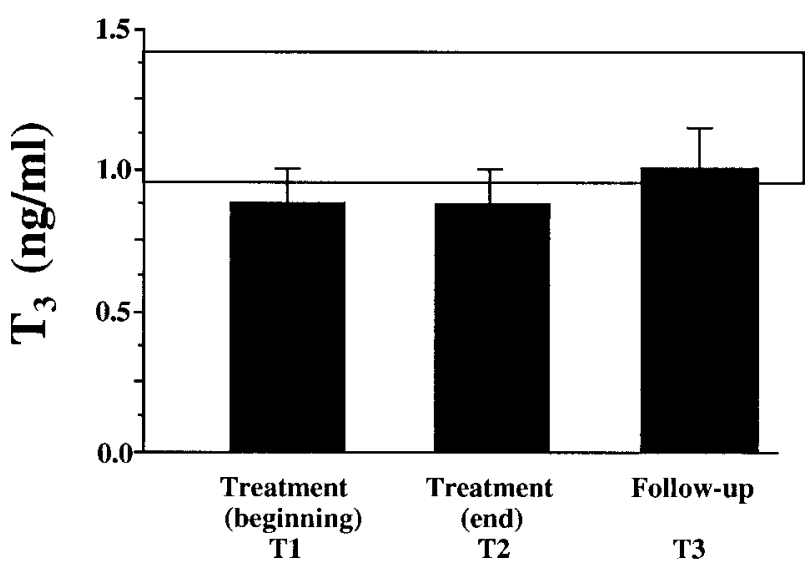

Figure 2 Schematic representation of mean \pm S.D. serum levels of total $T_{3}$ in patients with AN. Initial, final and follow-up periods in estrogen-treated patients. The horizontal bar represents the normal mean.

year of treatment. After the follow-up period the mean BMD in the 12 patients that completed the study was $-2.1 \pm 0.8$ S.D. (range -3.5 to -0.4 S.D.; Fig. 3). There was no difference in the mean BMD of these 12 patients at any stage of the study. Of the 38 patients starting the study, $62 \%$ had a BMD between -1 s.D. and -2.5 S.D. and $38 \%$ had a BMD $<-2.5$ S.D. No significant correlation was found between the BMD and the duration of the amenorrhea, BMI, estradiol levels, calcium phosphate metabolites or IGF-I levels. However, a significant correlation was found between the BMD and $\mathrm{T}_{3}$ levels $(r=0.59, \mathrm{P}<0.01)$.

\section{Discussion}

In this prospective study of 38 young women with AN, we demonstrated a profound reduction in BMD. Thirtyeight percent of the patients had a BMD greater than

Table 2 Estradiol, $T_{3}, T_{4}, T S H$ and IGF-I serum levels. Values are means \pm S.E.M.s.

\begin{tabular}{|c|c|c|c|c|c|}
\hline & $\begin{array}{l}\text { Estradiol } \\
(\mathrm{pg} / \mathrm{ml})\end{array}$ & $\begin{array}{c}\mathbf{T}_{\mathbf{3}} \\
(\mathrm{ng} / \mathrm{ml})\end{array}$ & $\begin{array}{c}\mathbf{T}_{4} \\
(\mathrm{ng} / \mathrm{ml})\end{array}$ & $\begin{array}{c}\text { TSH } \\
(\mathrm{mlU} / \mathrm{ml})\end{array}$ & $\begin{array}{l}\text { IGF-I } \\
(\mathrm{ng} / \mathrm{ml})\end{array}$ \\
\hline Initial $(n=38)$ & $24 \pm 8$ & $0.8 \pm 0.2$ & $6.6 \pm 1.0$ & $1.8 \pm 0.7$ & $334 \pm 113$ \\
\hline Final $(n=22)$ & $28 \pm 15$ & $0.9 \pm 0.1$ & $7.0 \pm 1.0$ & $1.5 \pm 0.6$ & $349 \pm 113$ \\
\hline Follow-up $(n=12)$ & $25 \pm 18$ & $1.1 \pm 0.1$ & $7.0 \pm 1.0$ & $1.8 \pm 0.5$ & $361 \pm 66$ \\
\hline
\end{tabular}




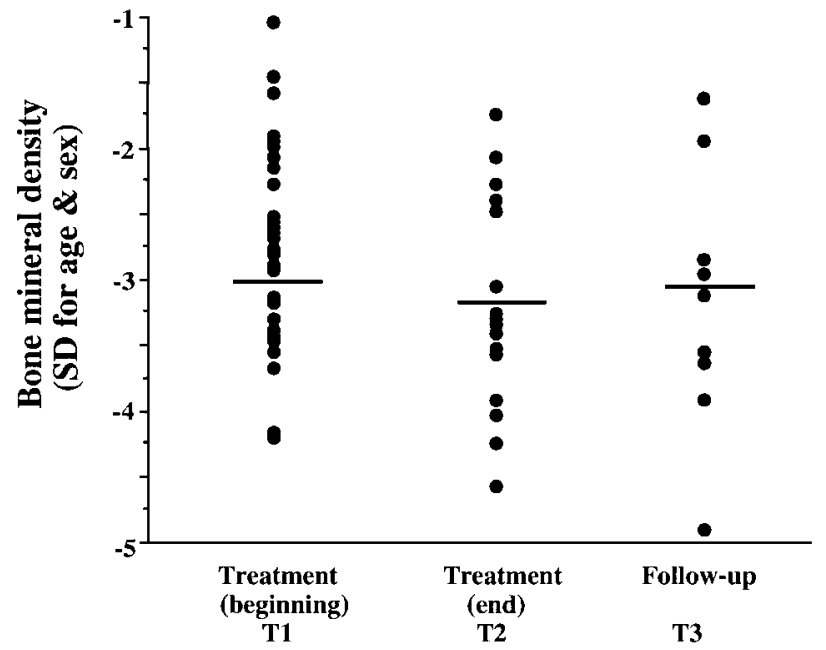

Figure 3 Schematic representation of BMD expressed in S.D. with respect to age and sex, in patients with AN. Initial, final and follow-up periods in estrogen-treated patients.

2.5 S.D. below normal, with $62 \%$ having a BMD between -1 and -2.5 S.D. for their age and sex according to the criteria of the World Health Organization (8). The estrogen-treated group had no significant change in BMD even after the follow-up period and partial weight recovery. This report confirms the progressive loss of trabecular bone in adult women with chronic AN and prolonged amenorrhea. We found that, in contrast to the beneficial effects of estrogen during menopause, young women with AN have persistent osteopenia despite estrogen replacement. No further deterioration of the BMD appeared to take place. Unfortunately, we cannot evaluate this statistically due to the lack of an adequate control group of patients with $\mathrm{AN}$ of similar characteristics.

Reduced bone mass in young women with AN has been clearly shown in several cross-sectional studies; however, few prospective data are available regarding the natural process of bone loss $(3,4,9,10)$. The more precocious the amenorrhea, the more severe the osteopenia and if menarche was never achieved the osteopenia is even more severe. Furthermore, the longer the period of amenorrhea the more severe the osteopenia. The long-term outcome of osteopenia in these patients is not well known. Rigotti et al. (11), in a longitudinal study of 27 adult women with $\mathrm{AN}$, found no improvement in the BMD after a period of 25 months, in spite of the fact that most of the patients gained weight and some even menstruated spontaneously. In 15 adolescents with AN followed during a period of 12-16 months, Bachrach et al. (12) observed an increase in BMD in relationship to the weight increase. Nevertheless, at the end of the study, osteopenia persisted in approximately $50 \%$ of the patients. Although more studies are necessary to establish with clarity the factors involved in the evolution of osteopenia, the available data suggest that the recovery age could be one of the most important factors in predicting the long-term outcome of these patients (13). This hypothesis would be in agreement with the physiological aspects of bone mass acquisition that suggest that there is a critical period after which the possibility of recovering bone mass could be very reduced.

The therapeutic potential of estrogens in treating osteopenia of patients with AN and extended amenorrhea is controversial (14). Most studies indicate that the spontaneous recovery of menstruation is accompanied by a significant improvement in BMD. On the contrary, and in agreement with our findings, estrogen therapy does not seem to induce a meaningful recovery of the $\operatorname{BMD}(3,4,15)$ and several possibilities could explain this failure. One possibility is that the estrogen dose which is effective in treating postmenopausal women is inadequate in a younger population. Second, whether continued improvement in bone mass may be seen in patients treated for a longer period of time than the current study is unknown. A third and more likely explanation is that estrogen therapy alone cannot correct the multiple factors contributing to bone loss in women with AN. In addition to profound hypoestrogenism, nutritional and other hormonal variables have been implicated in the pathogenesis of bone loss (16). These factors, including IGF-I deficiency, cortisol excess and decreased androgen production, are unaffected by estrogen administration and may have a continuing deleterious effect on bone mass (17).

Nutritional factors are important in regulating the growth and mineralization of bone and provide the substances necessary for this process (18). Other systemic hormones, including growth hormone $(\mathrm{GH})$, growth factors such as IGF-I, insulin, thyroid hormones, androgens, estrogens and glucocorticoids, are also implicated (19).

One of the most important agents in the regulation of skeletal growth and mineralization is IGF-I. Circulating IGF-I exerts both autocrine and paracrine functions (20). Our patients had reduced IGF-I levels at all three time points of the study. The finding of low levels of IGF-I in patients with AN, as in other situations of malnutrition, has been widely described in the literature (21). However, the pathophysiological mechanisms that mediate this phenomenon are only partially known (22). Surprisingly, in spite of partial weight recovery a simultaneous recovery of IGF-I levels is not seen. It is possible that this recovery is insufficient in either time or extent to overcome the numerous mechanisms that are underway in these patients. Grinspoon et al. (23) subcutaneously administered recombinant IGF-I for 6 days to 23 women with AN who had a $54 \%$ decrease in BMD. This resulted in an increase of the markers of both bone production and resorption.

Alterations of the thyroid axis in malnutrition are controversial (24). In our study, $\mathrm{T}_{3}$ levels were low at 
the beginning of treatment, within the low limits of normality during 1 year of treatment and were normalized after the follow-up period. This could be involved in the loss of bone mass in this group of patients since thyroid hormones exert biological effects on the growth cartilage by stimulating mineralization of the matrix, as well as on the formation and reabsorption of bone (25).

Insufficient nutrient intake inhibits the secretion of gonadotropins, preventing or delaying the onset of puberty. In addition to effecting low IGF-I levels, this results in a smaller growth spurt and a lower mineral deposit in the bone mass, as observed in these patients (26). Sex steroids promote skeletal restoration, bone mineralization and the growth spurt. The effects of sex steroids on the acquisition of bone mass can be direct, as well as indirect through modulation of local growth factors, GH, IGF-I and 1-25-OH vitamin D (27). Their influence on the acquisition and maintenance of the bone mass has been widely demonstrated in postmenopausal women. However, in patients with AN they do not seem to stimulate a significant increase in bone mass (28). Other factors, such as low calcium intake and low levels of IGF-I, are most likely implicated and the presence of estrogens is necessary, but not sufficient, for adequate mineralization (29). Recent studies suggest that the administration of other sex steroids, such as dehydroepiandrosterone (DHEA), most likely acting through aromatization to estrogen in peripheral tissues, could be used to treat these patients. Indeed, DHEA stimulates human osteoblast cell proliferation through the androgen receptor and preliminary findings suggest that DHEA has both anabolic and anti-osteolytic properties. Longitudinal studies are needed to determine the long-term biological actions of this agent, including its effects on bone mass (30).

As we have previously demonstrated, leptin levels in patients with AN are significantly reduced, as might be expected in light of their dramatically reduced levels of body fat (31). However, there was no significant correlation between BMI-SDS and leptin levels in these patients. Surprisingly, leptin levels did not rise significantly after recuperation of at least $10 \%$ of the original body mass (31). Even those patients who achieved a BMI within the normal range did not exhibit significant increases in their leptin levels. One possible explanation may be that these patients must maintain a normal body weight for a longer period of time in order to return their leptin levels to normal. Another possibility is that total leptin levels in these patients do not rise significantly with partial weight recovery, but that the proportion of this protein in the free, or presumably biologically active fraction, does increase. These possibilities deserve further investigation.

In conclusion, our data demonstrate that despite its usefulness in perimenopausal women, estrogen and gestagen administration does not reverse the profound osteopenia seen in young women with AN. Trabecular bone loss is severe and may progress despite estrogen therapy. Other factors, such weight loss, duration of the amenorrhea and low IGF-I levels, could contribute to the loss of bone mass in women with AN. Future investigation is needed to address the effect of early intervention on preserving bone mass in this increasing population of young women.

\section{Acknowledgements}

The authors would like to thank Dr J. A. Chowen for the critical review of the manuscript. This work was supported by grants from the Comunidad of Madrid and Fundación Endocrinología y Nutrición.

\section{References}

1 Carmichael KA \& Carmichael DH. Bone metabolism and osteopenia in eating disorders. Medicine 199574 254-267.

2 Muñoz MT, Morandé G, García-Centenera JA, Hervás F \& Argente J. Implications of calcium phosphate metabolism in the development of osteopenia in adolescents with anorexia nervosa. Hormone Research 199646 (Suppl 2) 327.

3 Klibanski A, Biller BM, Schoenfeld DA, Herzog DB \& Saxe VC. The effects of estrogen administration on trabecular bone loss in young women with anorexia nervosa. Journal of Clinical Endocrinology and Metabolism $1995 \mathbf{8 0} 898-904$.

4 Soyka LA, Grinspoon S, Levitsky LL, Herzog DB \& Klibanski A. The effect of anorexia nervosa on bone metabolism in female adolescents. Journal of Clinical Endocrinology and Metabolism $19998 \mathbf{4}$ 4489-4496.

5 Diagnostic and Statistical Manual of Mental Disorders, edn 4. Washington DC: American Psychiatry Association, 1994.

6 Hernández M, Castellet J, Narvaiza JL, Rincòn JM, Rviz I \& Sanchez E. Curvas y tablas de crecimiento. Eds M Hernández \& Fundación F Orbegozo. Madrid: Editorial Garsi, 1988.

7 Del Río L, Carrascosa A, Pons F, Gusinyé M, Yeste D \& Domenech FM. Bone mineral density of the lumbar spine in white Mediterranean Spanish children and adolescents: change related to age, sex and puberty. Pediatric Research $199435362-366$.

8 WHO Study Group. Assessment of fracture risk and its application to screening for postmenopausal osteoporosis. World Health Organization Technical Report Series 1994843 1-129.

9 Gulekli B, Davies MC \& Jacobs HS. Effect of treatment on established osteoporosis in young women with amenorrhea. Clinical Endocrinology $1994 \mathbf{4 1} 275-281$.

10 Bachrack LK, Guido D, Katzman D, Litt Y \& Marcus R. Decreased bone density in adolescent girls with anorexia nervosa. Pediatrics $199086440-442$.

11 Rigotti NA, Nussbaum SR, Herzog DB \& Neer RM. Osteoporosis in women with anorexia nervosa. New England Journal of Medicine $19843111601-1606$.

12 Bachrach LK, Katzman DK, Litt IF, Guido D \& Marcus R. Recovery from osteopenia in adolescent girls with anorexia nervosa. Journal of Clinical Endocrinology and Metabolism $199172602-606$.

13 Recker RR, Davies KM \& Hinders SM. Bone gain in young adult women. JAMA $1992 \mathbf{2 6 8} 2403-2408$.

14 Golden NH, Jacobson MS, Schebendach J, Solanto MV, Hertz SM \& Shenker IR. Resumption of menses in anorexia nervosa. Archives of Pediatric Adolescent Medicine 1997151 16-21.

15 Hergenroeder AC. Bone mineralization, hypothalamic amenorrhea and sex steroid therapy in female adolescents and young adults. Journal of Pediatrics 1995126 683-689.

16 Lichtenbelt M, Heidendal GA \& Westerterp KR. Energy expenditure and physical activity in relation to bone mineral density in women with anorexia nervosa. European Journal of Clinical Nutrition $199751826-830$. 
17 Emans SJ, Grace E \& Hoffer FA. Estrogen deficiency in adolescents and young adults impacts on bone mineral content and effects of estrogen replacement therapy. Obstetrics and Gynecology $19907 \mathbf{7 6}$ 585-592.

18 Johnston GC, Miller JZ, Slemenda CHW, Resiter TK, Siu HUI D, Christian JC et al. Calcium supplementation and increase in bone mineral density in children. New England Journal of Medicine $199232782-87$.

19 Argente J \& Pozo J. Factores de crecimiento y nutrición: aspectos pediátricos. Endocrinología 199542 (Suppl 2) 33-38.

20 Seeman E, Szmukler GI \& Formica C. Osteoporosis in anorexia nervosa: the influence of peak bone density, bone loss, oral contraceptive and exercise. Journal of Bone Mineral Research 19927 $1467-1474$.

21 Muñoz MT \& Argente J. Anorexia nerviosa y bulimia nerviosa. In Tratado de Endocrinología Pediátrica y de la Adolescencia, pp. 1333-1351. Eds J Argente, A Carrascosa, R Gracia \& F Rodríguez. Barcelona: DOYMA, 2000.

22 Argente J, Caballo N, Barrios V, Muñoz MT, Pozo J, Chowen JA, Morandé G \& Hernández M. Multiple endocrine abnormalities in the growth hormone $(\mathrm{GH})$ and insulin-like growth factor (IGF) axes in patients with anorexia nervosa: effect of a short and long-term weight recuperation. Journal of Clinical Endocrinology and Metabolism 199782 2084-2092.

23 Grinspoon S, Baum H, Lee K, Anderson E, Herzog D \& Klibanski A. Effects of short-term recombinant human insulin-like growth factor I administration on bone turnover in osteopenic women with anorexia nervosa. Journal of Clinical Endocrinology and Metabolism $1996813864-3870$.

24 Croxson MS \& Ibbertson HK. Low serum triidothyronine $\left(\mathrm{T}_{3}\right)$ and hypothyroidism in anorexia nervosa. Journal of Clinical Endocrinology and Metabolism 197744 167-174.
25 Norris PD, O'Malley BP \& Palmer RL. The TRH test in bulimia and anorexia nervosa: a controlled study. Journal of Psychiatric Research $198519215-219$.

26 Grinspoon S, Herzog D \& Klibanski A. Mechanisms and treatment options for bone loss in anorexia nervosa. Psychopharmacology Bulletin 199733 399-404.

27 Guleki B, Davies MC \& Jacobs HS. Effect of treatment on established osteoporosis in young women with amenorrhea. Clinical Endocrinology $1994 \mathbf{4 1} 275-281$.

28 Karlsson MK, Weigall SJ, Duan Y \& Seeman E. Bone size and volumetric density in women with anorexia nervosa receiving estrogen replacement therapy and in women recovered from anorexia nervosa. Journal of Clinical Endocrinology and Metabolism 2000 $853177-3182$.

29 Castro J, Lázaro L, Pons F, Halperin Y \& Toro J. Predictors of bone mineral density reduction in adolescents with anorexia nervosa. Journal American Academy of Adolescent Psychiatry 200039 1365-1370.

30 Gordon CM, Grace E, Emans SJ, Goodman E, Crawford MH \& Leboff MS. Changes in bone turnover markers and menstrual function after short-term oral DHEA in young women with anorexia nervosa. Journal of Bone Mineral Research 199914 136-145.

31 Argente J, Barrios V, Chowen JA, Sinha MK \& Considine RV. Leptin plasma levels in healthy Spanish children and adolescents, children with obesity and adolescents with anorexia nervosa and bulimia nervosa. Journal of Pediatrics $1997131833-838$.

Received 9 February 2001

Accepted 17 September 2001 